\title{
SPECTROSCOPIC CHARACTERIZATION OF SCHIFF BASE-COPPER COMPLEXES IMMOBILIZED IN SMECTITE CLAYS ${ }^{\#}$
}

Patrícia M. Dias, Lilian Kinouti, Vera R. L. Constantino e Ana M. D. C. Ferreira*

Departamento de Química Fundamental, Instituto de Química, Universidade de São Paulo, Av. Prof. Lineu Prestes, 748, 05508-900 São Paulo - SP, Brasil

Marcos B. Gonçalves, Rafael R. do Nascimento, Helena M. Petrilli e Marília Caldas

Instituto de Física, Universidade de São Paulo, CP 66318, 05315-970 São Paulo - SP, Brasil

Regina C. G. Frem

Instituto de Química de Araraquara, Universidade Estadual Paulista, CP 355, 14801-970 Araraquara - SP, Brasil

Recebido em 5/7/10; aceito em 17/9/10; publicado na web em 25/10/10

\begin{abstract}
Herein, the immobilization of some Schiff base-copper(II) complexes in smectite clays is described as a strategy for the heterogenization of homogeneous catalysts. The obtained materials were characterized by spectroscopic techniques, mostly UV/Vis, EPR, XANES and luminescence spectroscopy. $S W y-2$ and synthetic Laponite clays were used for the immobilization of two different complexes that have previously shown catalytic activity in the dismutation of superoxide radicals, and disproportionation of hydrogen peroxide. The obtained results indicated the occurrence of an intriguing intramolecular redox process involving copper and the imine ligand at the surface of the clays. These studies are supported by computational calculations.
\end{abstract}

Keywords: Schiff base-copper complexes; smectite clays; DFT calculation.

\section{INTRODUCTION}

The immobilization of catalytic species in two dimensional inorganic matrices has been studied for a long time as a strategy for the heterogenization of homogeneous catalysts, in order to facilitate the separation of products, and improve robustness, selectivity, and recycling of the catalyst. Clays have been widely used as catalysts or catalyst supports. ${ }^{1}$ Particularly, smectite-type clays having metal ions incorporated or immobilized in its structure can act as efficient catalysts in different processes of industrial or environmental relevance, due to their unique physicochemical properties, such as swelling, cation exchange capability, mechanical and thermal stability. ${ }^{2-4}$ Nickel incorporated in smectite was active in the steam reforming of acetic acid, for the production of hydrogen, ${ }^{5}$ while Ni-containing smectite prepared by hydrothermal method showed to be an efficient catalyst in the reforming of methane with carbon dioxide. ${ }^{6}$ Also, cobaltcontaining mesoporous smectite-type clays MST(Co) were prepared and applied for hydrodesulfurization of thiophenic compounds, which are model organic sulfur compounds in petroleum feedstock. ${ }^{7}$ On the other hand, a manganese-porphyrin immobilized in smectite clay montmorillonite was found to be a stable, recyclable, and efficient catalyst for the $\mathrm{H}_{2} \mathrm{O}_{2}$-catalyzed oxidation of lignins, or representative lignin model compounds. ${ }^{8}$ Bis(oxazoline)-copper complexes, immobilized by electrostatic interactions on Laponite, were tested as catalysts in the cyclopropanation of styrene with ethyl diazoacetate, showing low yields $(\sim 30 \%)$ and substantial changes in selectivity depending on the solvent and dimensionality of the support. ${ }^{9}$ However, when an iminobis(oxazoline)copper(II) complex was used, in spite of a quite slow reaction rate, the enantioselectivities observed were very high (90\% for isomer trans, and $84 \%$ for isomer cis). ${ }^{9}$

The growing interest on copper complexes with various $\mathrm{N}$-donor ligands, especially di-imines, comes mainly from their capability of combining characteristic structural flexibility, mimicking of protein

*e-mail: amdcferr@iq.usp.br

"Dedicated to Professor Hans Viertler on the occasion of his $70^{\text {th }}$ birthday. active sites, ease of preparation, and stabilization of both oxidation states of the metal usual in biological systems. ${ }^{10}$ When reduced to copper(I) state they can additionally provide long-lived electronically excited states, and exhibit intense luminescence. ${ }^{11-13}$ The redox potential of acyclic and macrocyclic Schiff base complexes has deserved a strong interest since it seems to be directly related to some of the biologically important properties of this type of compounds. Mostly, Schiff-base copper complexes have been intensively investigated as enzyme mimics by their dioxygen binding ability, and catalytic activity in oxidative processes. ${ }^{14,15}$

Some acyclic Schiff base copper(II) complexes were investigated in our laboratory as superoxide dismutase and catalase mimics, promoting the dismutation of superoxide radicals (SOD activity), and the disproportionation of hydrogen peroxide (catalase activity). ${ }^{16,17}$ Additionally, these studies revealed that they are capable of generating reactive oxygen species (ROS), in the presence of hydrogen peroxide. ${ }^{18}$ All those results indicated a modulation of their chemical properties, both antioxidant and pro-oxidant, by the imine ligand. Further, a copper(II) complex of this type, with a tridentate imine, was intercalated in niobate nanoscrolls and revealed to be an efficient catalyst for phenol oxidation using hydrogen peroxide as oxidant. ${ }^{19}$

Herein, the immobilization of these previously studied Schiff base-copper(II) complexes in smectite clays are reported. Clay structure is formed by sheets of $\left[\mathrm{SiO}_{4}\right]$ tetrahedra and $\mathrm{Mg}(\mathrm{OH})_{2}$ or $\mathrm{Al}(\mathrm{OH})_{3}$ octahedra. These sheets may share oxygen atoms between one tetrahedral e one octahedral sheet, or with an octahedral sheet sandwiched between two tetrahedral sheets (Figure 1A) ${ }^{20}$ The isomorphic substitution of $\mathrm{Si}, \mathrm{Al}$ and/or $\mathrm{Mg}$ by ions supporting smaller charge originates a negative charge in the lamellae that is neutralized by hydrated cations. Commercial clay $S W y-2$ and synthetic Laponite were used as inorganic matrices for the insertion of the cationic copper(II) complexes with di-imine ligands (Figure 1B): $N, N^{\prime}$-bis(2pyridyl)methylene-1,2-diaminoethane]-( $N, N$ ', $N$ ', $N$ '" ')-copper(II) (abbreviated $\left.[\mathrm{Cu}(\text { pyalen })]^{2+}\right)$, and $\left[N, N^{\prime}\right.$-bis(2-acetylpyrazyl) methylene-1,3-diaminopropane]-( $N, N^{\prime}, N^{\prime}, N^{\prime \prime}$ ')-copper(II) (abbreviated $\left.[\mathrm{Cu}(\text { apzpn })]^{2+}\right)$. The obtained materials were characterized 
by spectroscopic techniques, mostly UV/Vis electronic absorption, electronic paramagnetic resonance (EPR), X-ray absorption near edge structure (XANES), and luminescence spectroscopy (PLS). The obtained results indicated the occurrence of an intriguing intramolecular redox process at the surface of the clay, with reduction of the metal ion and simultaneous oxidation of the coordinated ligand. Theoretical calculations for both copper complexes in oxidized and reduced state were also carried out in order to support the experimental data.

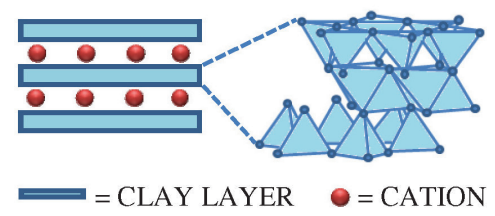

(A)

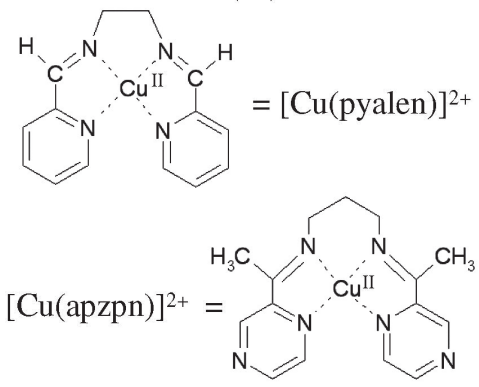

(B)

Figure 1. Schematic structure of clays (A) and cationic Schiff base-copper(II) complexes $(B)$

\section{EXPERIMENTAL}

\section{Copper complexes preparation}

Copper(II) complexes with di-imine ligands, N,N'-bis(2pyridyl)methylene-1,2-diaminoethane]- (N,N',N",N"')-copper(II) (abbreviated pyalen) and [N,N'-bis(2-acetylpyrazyl)methylene-1,3diaminopropane]-(N,N',N",N",')-copper(II) (abbreviated apzpn) were synthesized as perchlorate salts, as previously reported. ${ }^{16}$

\section{$[\mathrm{Cu}($ pyalen $)]\left(\mathrm{ClO}_{4}\right)_{2}$}

$0.14 \mathrm{~mL}$ of 1,2-diaminoethane (Riedel de Haënag) was dissolved in $3 \mathrm{~mL}$ of ethanol (Merck). To this solution, $0.38 \mathrm{~mL} \mathrm{2-pyridine}$ carboxyaldehyde (Aldrich) was added. The system was stirred and kept under reflux $\left(78{ }^{\circ} \mathrm{C}\right)$ for $1 \mathrm{~h}$. After cooled to $35^{\circ} \mathrm{C}, 0.120 \mathrm{~g}(2$ mmols) of $\mathrm{Cu}\left(\mathrm{ClO}_{4}\right)_{2} \cdot 6 \mathrm{H}_{2} \mathrm{O}$ (Aldrich), dissolved in $10 \mathrm{~mL}$ deionized water, was added. The system was cooled in an ice bath and the blue solid formed was then filtered, and dried under low pressure (yield: $70 \%$ ). Elemental analysis data obtained were consistent with calculated values considering the formula $[\mathrm{Cu}($ pyalen $)]\left(\mathrm{ClO}_{4}\right)_{2}(\mathrm{MW}=$ $500.73 \mathrm{~g} / \mathrm{mol}$ ): Exp. C, $33.7 \%$; H, 3.10\%; N, $12.1 \%$; Calc., C, $33.6 \%$; $\mathrm{H}, 2.82 \% ; \mathrm{N}, 11.2 \%$.

\section{$[\mathrm{Cu}($ apzpn $)]\left(\mathrm{ClO}_{4}\right)_{2}$}

$1.780 \mathrm{~g}(4 \mathrm{mmols})$ of $\mathrm{Cu}\left(\mathrm{ClO}_{4}\right)_{2} \cdot 6 \mathrm{H}_{2} \mathrm{O}$ were dissolved in $10 \mathrm{~mL}$ deionized water, and added under stirring to acetylpyrazine (Aldrich). After $5 \mathrm{~min}, 0.33 \mathrm{~mL}$ of 1,3-diaminepropane (Aldrich) was slowly added to the copper solution. The mixture was kept under mild heating $\left(50{ }^{\circ} \mathrm{C}\right)$ for $10 \mathrm{~min}$, and the formation of a brown solid was observed. The reaction flask was cooled on ice for $1 \mathrm{~h}$. The precipitate formed was filtered, and washed with cold deionized water and ethanol. The isolated solid was dried in a desiccator under low pressure (yield 22\%). Elemental analysis data were consistent with calculated values for the formula $[\mathrm{Cu}(\mathrm{apzpn})]\left(\mathrm{ClO}_{4}\right)_{2} \cdot 2 \mathrm{H}_{2} \mathrm{O}(\mathrm{MW}=$ 582.26 g/mol): Exp., C, 31.9\%; H, 3.47\%; N, $12.9 \%$; Calc., C, $31.2 \%$; $\mathrm{H}, 3.12 \%$; N, $14.4 \%$.

\section{Copper complexes immobilization into clay matrices}

Copper complexes were immobilized by ion-exchange reaction into the natural montmorillonite clay SWy-2 (supplied by the Clays Minerals Society, USA) and the synthetic hectorite clay Laponite RD (supplied by Laporte Inorganics, UK, and here abbreviated LPN). SWy-2 clay was changed to the sodium form, as it was previously described in the literature, ${ }^{21}$ and kept in a water suspension containing $26 \mathrm{~g}$ of clay per liter of suspension. LPN was used as received.

In a $250 \mathrm{~mL}$ round bottom flask, $1 \mathrm{~g}$ of LPN was slowly added to $150 \mathrm{~mL}$ of desionized water, under stirring. $50 \mathrm{~mL}$ of the $\mathrm{SWy}-2$ clay suspension was used in the immobilization process. The [Cu(pyalen)] $\left(\mathrm{ClO}_{4}\right)_{2}$ complex was dissolved in $10 \mathrm{~mL}$ of desionized water, and then slowly added to the clay suspension. In the case of [Cu(apzpn)] $\left(\mathrm{ClO}_{4}\right)_{2}$, it was dissolved in $10 \mathrm{~mL}$ of acetonitrile (Aldrich). A reflux was mounted and the complex/clay system was kept in a water-bath mild heating $\left(50{ }^{\circ} \mathrm{C}\right)$ for a week. The amount of copper complexes used in the experiments was calculated based on the cation exchange capacity (CTC) of the clay matrices (LPN: $50 \mathrm{mmol} / 100 \mathrm{~g}$ and SWy-2: $35 \mathrm{mmol} / 100 \mathrm{~g})$. In the case of LPN, $18 \%$ of the clay's CTC was neutralized by the cationic copper complexes and $26 \%$ for the SWy-2. The complex/clay solids were washed using a dialysis membrane, against deionised water, to remove the sodium and perchlorate ions from the system, and then dried by freeze-drying. The isolated materials were abbreviated $[\mathrm{Cu}($ pyalen $)] / \mathrm{LPN},[\mathrm{Cu}($ apzpn) $)] / \mathrm{LPN}$, $[\mathrm{Cu}$ (pyalen)]/SWy-2 and [Cu(apzpn)]/SWy-2.

\section{Samples characterization}

Elemental analysis $(\mathrm{C}, \mathrm{H}, \mathrm{N})$ were conducted on a Perkin Elmer 2400 analyzer at the Central Analítica (IQ - USP). UV/Vis electronic absorption spectra of the copper complexes solutions, the colloidal clay aqueous dispersions, and also the diffuse reflectance spectra of solid samples were recorded in a Shimadzu, mod. UV-2401PC spectrophotometer equipped with integration sphere of barium sulfate. To record the diffuse reflectance spectra, solid samples were diluted with $\mathrm{BaSO}_{4}$ (Waco Pure Chem. Co.). X-ray diffraction (XRD) patterns of powdered samples were registered on a Philips diffractometer, model X'PERT-MPD using $\mathrm{Cu}-\mathrm{K}_{\alpha}$ radiation (1.541 $\mathrm{A}, 40 \mathrm{kV}$ and $40 \mathrm{~mA}$ ).

$\mathrm{X}$-ray absorption spectroscopy experiments were performed on the XAS beam line of the Brazilian Synchrotron Light Laboratory (LNLS, Campinas, Brazil) $1.37 \mathrm{GeV}$ storage ring. The X-ray absorption near edge structure (XANES) spectra were recorded at the $\mathrm{Cu}$ K-edge (8979 eV), between $8920 \mathrm{eV}$ and $9050 \mathrm{eV}$ (0.5 eV step, 2 seconds acquisition time, $500 \mathrm{~ms}$ accommodation time). XANES spectra of the complex/clay solids were recorded by the fluorescence mode while the solid free copper(II) complexes spectra were recorded using the transmission mode. Spectrum of a metallic copper foil was recorded before the recording of each sample spectrum, for calibration. The spectra were normalized to give an unitary absorption jump.

EPR spectra were registered at $77 \mathrm{~K}$ (liquid $\mathrm{N}_{2}$ ) in a Bruker EMX instrument, operating at $9.34 \mathrm{GHz}$, with $100 \mathrm{MHz}$ modulation frequency, and $20 \mathrm{~mW}$ power. Modulation amplitude of $15 \mathrm{G}$ was usually used for solid samples, in Wilmad quartz tubes. DPPH $(\alpha, \alpha$ '-diphenyl- $\beta$-picrylhydrazyl) was used as reference standard. Oriented films of the copper complex/clay samples were prepared as follow: suspensions containing $1 \%(\mathrm{~m} / \mathrm{v})$ of complex/SWy-2 sample, 
or $0.125 \%$ of complex/LPN sample (after keeping the systems under magnetic stirring for $24 \mathrm{~h}$, for the solids disaggregation in water) were dropped in sheets of cellulose acetate. Suspensions were dried at room temperature producing uniform films on the polymer sheet. These films were supported in quartz supporting tubes, and oriented perpendicular or parallel to the magnetic field, and had their EPR spectra registered.

Photoluminescence experiments were realized at room temperature on a SPEX Fluorolog F212I spectrofluorimeter using a $450 \mathrm{~W}$ xenon lamp and a Hammamatsu R928 photomultiplier. Grounded samples were placed in a quartz tube and the signal was collected at a $24.5^{\circ}$ angle from the incident beam.

\section{Theoretical calculations}

In order to verify the structural and electronic differences between $[\mathrm{Cu}(\text { pyalen })]^{\mathrm{n}+}$ and $[\mathrm{Cu}(\text { apzpn })]^{\mathrm{n}+}$ we have performed electronic structure calculations for the charge states $n=1+$ and $n=2+$ and spin configurations singlet $(S=0)$ and doublet $(S=1 / 2)$ (Figure 4). The Projector Augmented Wave (PAW) method in the Car-Parrinello scheme was used, as embodied in the CP-PAW ${ }^{22}$ computational code, to obtain the ground state geometries. PAW is an all-electron $\mathrm{k}$-space self-consistent method performed in the Kohn Sham scheme ${ }^{23}$ of the density functional theory (DFT), and the Perdew-Burke-Ernzerhof $(\mathrm{PBE})^{24}$ generalized gradient approximation for the exchange and correlation functional was applied. A detailed description of the theoretical procedure used here can be found elsewhere. ${ }^{25,26}$ For easy reference, some important quantities defining the PAW basis set were used: one $s$ projector function per angular momentum for the hydrogen atom, two $s$, two $p$ and one $d$ for carbon and nitrogen atoms, and one extra $d$ projector function for the $\mathrm{Cu}$ atom and the plane waves basis cutoff energy of $40 \mathrm{Ry}$.

\section{RESULTS AND DISCUSSION}

Very significant visual change in the color of the $[\mathrm{Cu}(\text { pyalen })]^{2+}$ complex was observed during its ion-exchange immobilization in the smectite Laponite and SWy-2 clays. This copper(II) complex shows a light blue color in water solution. During the immobilization process in Laponite, for example, its color changes initially to lilac, and goes forward to an intense red color. The modifications in the aqueous dispersion of Laponite containing the $[\mathrm{Cu}(\text { pyalen })]^{2+}$ complex were monitored by UV/Vis electronic absorption spectroscopy, as shown in Figure 2.

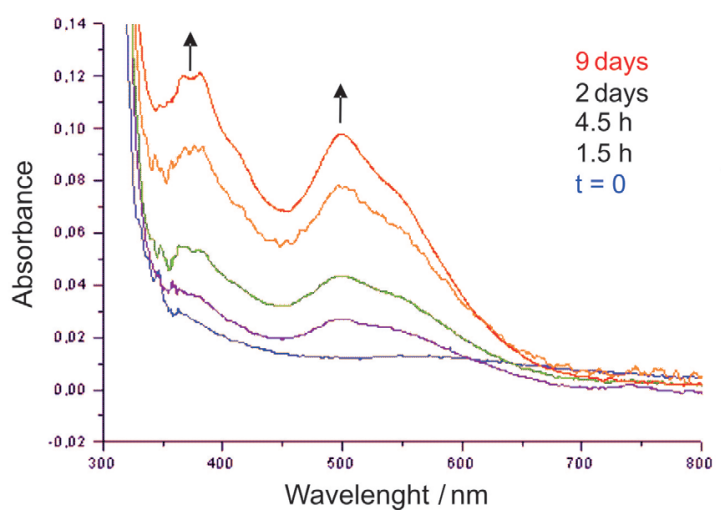

Figure 2. Changes in electronic absorption spectra with time of aqueous dispersion of $\left[\mathrm{Cu}(\text { pyalen }]^{2+}\right.$ complex and LPN clay at room temperature

$[\mathrm{Cu}(\text { pyalen })]^{2+}$ complex spectrum showed absorption bands at about $610 \mathrm{~nm}$ (assigned to the characteristic metal d-d electronic transition), and in the UV region (attributed to internal transitions in the Schiff base ligand). ${ }^{17}$ After the copper complex immobilization in Laponite clay by ion-exchange reaction, the spectrum exhibited strong absorptions in the $490-550 \mathrm{~nm}$, and $360-380 \mathrm{~nm}$ spectral regions. Similar alterations were observed for $[\mathrm{Cu}(\text { pyalen })]^{2+}$ complex in SWy-2 suspension, but the blue color progressed to rose. On the contrary, no significant color modifications were observed in the aqueous clay suspensions containing the $[\mathrm{Cu}(\text { apzpn })]^{2+}$ complex. It was only noticed a tiny intensification in the brown color of this complex in water medium. Table 1 shows the UV/Vis spectral data for the free and immobilized metal complexes in Laponite and SWy-2 clays.

Table 1. UV/Vis electronic absorption bands of the copper complexes in aqueous solution, and immobilized in clay matrices

\begin{tabular}{|c|c|c|}
\hline & & Maximum absorption/nm \\
\hline \multirow[t]{5}{*}{$\begin{array}{l}{[\mathrm{Cu}(\text { pyalen })]^{2+}} \\
\text { system }\end{array}$} & In aqueous solution & $\begin{array}{l}230\left(1.9 \times 10^{4}\right)^{(a)} ; 275 \\
\left(7.88 \times 10^{3}\right) ; 610(112)\end{array}$ \\
\hline & $\begin{array}{l}\text { In aqueous suspension of } \\
\text { LPN }\end{array}$ & $\begin{array}{c}356 ; 379 ; 497 \text { (shoulder at } \\
550)\end{array}$ \\
\hline & In solid state $\left(\mathrm{ClO}_{4}^{-} \text {form }\right)^{(\mathrm{b})}$ & 588 \\
\hline & [Cu(pyalen)]/LPN solid ${ }^{(b)}$ & 500 \\
\hline & {$\left[\mathrm{Cu}(\right.$ pyalen) $] / \mathrm{SWy}-2$ solid $^{(\mathrm{b})}$} & 541 \\
\hline \multirow[t]{5}{*}{$\begin{array}{l}{[\mathrm{Cu}(\text { apzpn })]^{2+}} \\
\text { system }\end{array}$} & In aqueous solution & $\begin{array}{l}213\left(1.42 \times 10^{4}\right) ; 269 \\
\left(1.69 \times 10^{4}\right) ; 646(60)\end{array}$ \\
\hline & $\begin{array}{l}\text { In aqueous suspension of } \\
\text { LPN }\end{array}$ & $215 ; 269$ \\
\hline & In solid state $\left(\mathrm{ClO}_{4}^{-} \text {form }\right)^{(\mathrm{b})}$ & 468 \\
\hline & Solid [Cu(apzpn)]/LPN ${ }^{(b)}$ & 468 (shoulder at 665) \\
\hline & Solid [Cu(apzpn)]/SWy-2 (b) & 468 (shoulder at 665) \\
\hline
\end{tabular}

(a) value in parenthesis is the molar absortivity $\left(\mathrm{M}^{-1} \mathrm{~cm}^{-1}\right)$. (b)diffuse reflectance spectra recorded in the visible region.

In the literature, a very similar copper(I)-di-Schiff base complex, $[\mathrm{Cu}(\text { Pupy })]^{+}$, where Pupy = 1,8-bis(2-pyridyl)-2,7-diazaoctadiene-1,7), has been obtained by reduction of the copper(II) precursor, also described as an efficient structural and functional analogue of SOD1 $\left(\mathrm{Cu}, \mathrm{Zn}\right.$ - superoxide dismutase). ${ }^{27}$ The crystal structures of both species were determined, indicating a monomeric square-planar tetrahedrally distorted compound for the oxidized species, and a helical structure for the dimeric red-brown reduced species. ${ }^{27}$ The dimeric copper(I) species formation is credited to the long chain imine ligand, allowing the coordination of the same ligand to both copper centers, and this reduced form exhibits a maximum absorption at $478 \mathrm{~nm}(\varepsilon$ $=13.6 \times 10^{3} \mathrm{M}^{-1} \mathrm{~cm}^{-1}$ ), in aqueous solution.

Some additional experiments were then conducted to know if the spectral changes in the $\mathrm{Cu}$ (pyalen)/clay systems are dependent of light or molecular oxygen present in air. When the immobilization reaction between the copper complex and Laponite was conducted in the dark, the spectral modifications were the same above described. However under molecular nitrogen atmosphere, the electronic spectrum of Laponite dispersion containing the $[\mathrm{Cu}(\text { pyalen })]^{2+}$ ion exhibited the same bands showed in Figure 2, plus one poorly defined absorption band in the region between 380 and $500 \mathrm{~nm}$, suggesting that molecular oxygen can have a limited involvement in the reaction process. Schiff base molecules can undergo spontaneous oxidation in presence of molecular oxygen through the incorporation of peroxide group in the $\mathrm{C}=\mathrm{N}$ bond. ${ }^{28}$ However, considering the experimental result under nitrogen gas, it is possible to state that the observed spectral modifications are not related to the ligand oxidation by atmospheric $\mathrm{O}_{2}$ molecule. Copper(II) aqua-complex (from chloride salt) was 
also immobilized by ion exchange in Laponite and Swy-2 clays, as a control, but in this case no color modification was observed (the isolated $\mathrm{Cu}^{2+} /$ clay solids kept this light blue color), indicating that both species, the metal ion and the Schiff base ligand, are connected to the spectral changes observed. Some research works have reported that organic aromatic molecules like benzene can be oxidized by $\mathrm{Cu}^{2+}$ ions intercalated into clay minerals..$^{29,30}$ Hence, the spectral modifications noticed in this work can be related to the occurrence of a redox reaction promoted by the inorganic host matrix, where the copper(II) complex is reduced to copper(I) and simultaneously the organic ligand is oxidized. In order to check this possibility, the EPR spectra of free and immobilized copper complex samples were recorded. Copper(II) ion is a paramagnetic species (electronic configuration $\mathrm{d}^{9}$ ) while copper(I) ion (electronic configuration $\mathrm{d}^{10}$ ) is EPR silent.

Table 2 shows the EPR data for the free and immobilized metal complexes in Laponite and SWy-2 clays. All the samples exhibited characteristic signals of mononuclear copper(II) ions, with tetragonal configuration, and spectroscopic parameters $g_{/ /}>g_{\perp}$. In solid state, an isotropic $\mathrm{g}$ was observed for the free $[\mathrm{Cu}(\text { pyalen })]^{2+}$ complex, while a hyperfine structure was detected for $[\mathrm{Cu}(\mathrm{apzpn})]^{2+} \cdot{ }^{16}$ For the intercalated species in SWy-2, the determined parameters were quite different of those for the corresponding free species, in solid state or frozen acetonitrile solution. In the case of complexes intercalated in LPN, two different sets of parameters were determined, indicating the presence of two different copper(II) species. It was also noticed that one of the species (parameters in bold) exhibited EPR signals circa 6-fold more intense than the other. This could be attributed to complexes inserted in distinct sites of the smectite structure, or to copper(II) ions coordinated to different ligands. Since EPR signals were detected for all the complex/clay samples, the copper ions in those materials have been only partially reduced, or reduced and subsequently somewhat re-oxidized.

The spectroscopic parameter ratio $\mathrm{g}_{/ /} / \mathrm{A}_{/ /}$is often used as an empirical evidence of tetrahedral distortion around the metal in copper(II) complexes. ${ }^{31}$ On comparing this ratio for the immobilized $[\mathrm{Cu} \text { (pyalen) }]^{2+}$ species in SWy-2 or LPN, the values obtained are not different from those in the free species, expected for an almost square- planar geometry. On the contrary, for immobilized $\left[\mathrm{Cu}(\text { apzpn) }]^{2+}\right.$ species in both clays a significant difference in those values was observed, indicative of a more accentuated tetrahedral distortion in the complex when interacting with the clay surface.

EPR spectra were also registered for oriented films of $[\mathrm{Cu}(\text { pyalen })]^{2+}$ in LPN, in order to obtain information about the geometrical orientation of the copper species inside the clay layers. As already described for other metal complexes, for example the copper(II) tetramethylpyridylporphyrin [CuTMPyP] in Na-hectorite or Li-fluorohectorite layers, ${ }^{32}$ only the $\mathrm{g}_{/ /}$component was observed when the film was oriented perpendicular to the applied magnetic field $\left(\mathrm{H}_{\mathrm{o}}\right)$ and, on the contrary, just the $\mathrm{g}_{\perp}$ component was detected if the film was parallel to the field. Only one of the signals was observed, depending on the $[\mathrm{Cu}$ (pyalen) $] /$ LPN film orientation, as shown in Figure 3. Those data are indicative of a parallel orientation of the complex (with a tetragonal geometry somewhat tetrahedrally distorted) regarding the LPN layers surface. Contrarily, for the [CuTMPyP]/fluorohectorite film no changes in the EPR spectrum were observed, indicating a $45^{\circ}$ orientation of the porphyrin ring regarding the basal plane of the clay. ${ }^{32}$

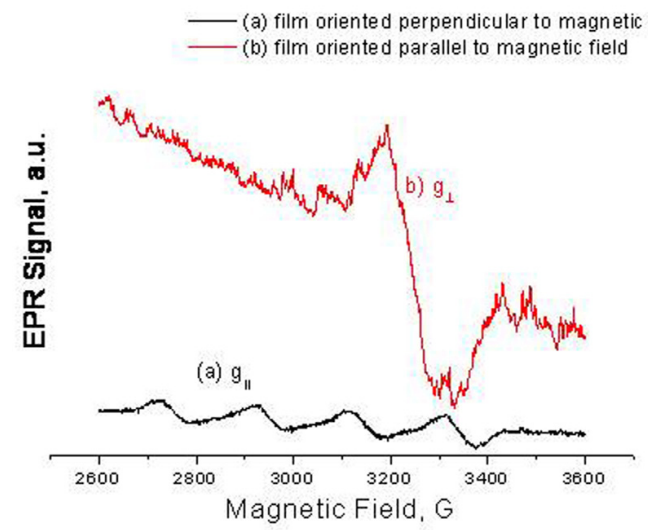

Figure 3. EPR spectra of $[\mathrm{Cu}(\text { pyalen })]^{2+}$ in Laponite film oriented in the magnetic field (perpendicular and parallel), at $77 \mathrm{~K}$

Table 2. EPR parameters for the copper complexes in aqueous solution, immobilized in clay matrices, and in LPN films

\begin{tabular}{|c|c|c|c|c|c|}
\hline Compound & & $\mathrm{g}_{\perp}$ & $\mathrm{g}_{/ /}$ & $\mathrm{A}_{/ /}, \mathrm{G}$ & $\mathrm{g}_{/ /} / \mathrm{A}_{/ /}, \mathrm{cm}$ \\
\hline \multirow[t]{6}{*}[\mathrm{Cu}(\text{pyalen})]{$^{2+}$ system } & In frozen $\mathrm{CH}_{3} \mathrm{CN}$ solution ${ }^{(\mathrm{a})}$ & 2.058 & 2.218 & 184 & 117 \\
\hline & In solid state $\left(\mathrm{ClO}_{4}^{-}\right.$form $)$ & 2.059 & 2.207 & & \\
\hline & In SWy-2 & 2.067 & 2.321 & 235 & 91 \\
\hline & In LPN & 2.061 & 2.193 & 197 & 108 \\
\hline & & & 2.257 & 221 & 97 \\
\hline & In $\mathrm{LPN}^{(\mathrm{b})}$ & 2.049 & 2.182 & 210 & 102 \\
\hline \multirow[t]{5}{*}[\mathrm{Cu}(\text{apzpn})]{$^{2+}$ system } & In frozen $\mathrm{CH}_{3} \mathrm{CN}$ solution ${ }^{(\mathrm{a})}$ & 2.063 & 2.229 & 190 & 113 \\
\hline & In solid state $\left(\mathrm{ClO}_{4}^{-}\right.$form $)$ & 2.082 & 2.239 & 186 & 115 \\
\hline & In SWy-2 & 2.099 & 2.297 & 153 & 140 \\
\hline & In LPN & 2.081 & 2.375 & 129 & 166 \\
\hline & & & 2.308 & 123 & 174 \\
\hline Film & orientation & $\mathrm{g}_{\perp}$ & $\mathrm{g}_{/ 1}$ & $\mathrm{~A}_{/ /}, \mathrm{G}$ & $\mathrm{g}_{/ /} / \mathrm{A}_{/ /}, \mathrm{cm}$ \\
\hline \multirow[t]{2}{*}[\mathrm{Cu}(\text{pyalen})]{$^{2+}$ in LPN } & Perpendicular to $\mathrm{H}_{\mathrm{o}}^{(\mathrm{c})}$ & ---- & 2.207 & 195 & 110 \\
\hline & Parallel to $\mathrm{H}_{\mathrm{o}}$ & 2.054 & --- & & \\
\hline \multirow[t]{2}{*}[\mathrm{Cu}(\text{apzpn})]{$^{2+}$ in LPN } & Perpendicular to $\mathrm{H}_{\mathrm{o}}$ & --- & 2.274 & 130 & 164 \\
\hline & Parallel to $\mathrm{H}_{\mathrm{o}}$ & 2.084 & --- & & \\
\hline
\end{tabular}

(a) as in ref. 16; (b) clay and metal complex mixed in aqueous solution, and spectra recorded after $4 \mathrm{~h}$. (c) $\mathrm{H}_{\mathrm{o}}$ represents the applied magnetic field. 
The interaction of the copper complex with the clay could be responsible for a higher stabilization of the resulting species, due to the substitution of water molecules in axial positions at the metal coordination sphere for oxygen ions localized at the clay surface. In the literature, the stability constant of the bis(ethylenediamine) copper(II) complex in clay surface was described as circa $10^{3}$ higher than that in aqueous solution. ${ }^{33}$

Theoretical results (in gas phase simulations) for the Schiff basecopper complexes were obtained after geometry optimization (Figure 4). It has been already shown that the PAW method is well suited to study ground state properties of metal complexes. ${ }^{25,26}$ Nevertheless, as it can occur, in the optimization procedure performed here it was noticed that two local potential energy minima exist, which are very close in energy, leading to the two final geometries for the $[\mathrm{Cu}(\text { pyalen })]^{2+}$ species shown in Figure $4 \mathrm{a}$ and $4 \mathrm{~b}$. The structure with lowest energy, shown in Figure $4 b$, is more distorted than the almost square planar, shown at Figure 4a, which is energetically less favored by $2.3 \mathrm{kcal} /$ mol. The structures of both complexes ( $4 \mathrm{~b}$ and $4 \mathrm{e}$ ) in the oxidized form (2+ charge state) exhibit a $\mathrm{N}_{4}$ square-planar coordination core with some tetrahedral distortion, with a $17.60^{\circ}$ torsion angle (between the four $\mathrm{N}$ atoms) for $[\mathrm{Cu} \text { (pyalen) }]^{2+}$ and $28.09^{\circ}$ for $[\mathrm{Cu}(\text { apzpn })]^{2+}$. On the other hand, structures ( $4 \mathrm{~d}$ and $4 \mathrm{f}$ ) corresponding to the analogous reduced form ( +1 charge state) show a more distorted $\mathrm{N}_{4}$ tetrahedral coordination, with a $42.76^{\circ}$ torsion angle in $[\mathrm{Cu}(\text { pyalen })]^{+}$and $42.44^{\circ}$ in $[\mathrm{Cu}(\mathrm{apzpn})]^{+}$. A similar behavior (smaller distortion for the oxidized form when compared to the reduced form), has been observed in analogous copper complexes, with longer chain imine ligands (four $\mathrm{CH}_{2}$ groups between the $\mathrm{N}$ coordinating atoms). ${ }^{27,31}$

Since here the focus is to investigate the behavior of these complexes immobilized in two dimensional inorganic matrices, some possible theoretical conformations were considered in order to calculate electronic and optical properties which are then compared to the available measurements. A relevant question to be addressed here is if the complexes can be accommodated between the clay layers. The thickness of the complexes was then estimated, considering the distance between the two most distant $\mathrm{H}$ atoms in the imine ligands. Those calculated distances were $2.94 \AA$ for $[\mathrm{Cu}(\text { pyalen })]^{2+}$ and 2.79 $\AA$ for $[\mathrm{Cu}(\mathrm{apzpn})]^{2+}$ (considering Figures $4 \mathrm{~b}$ and $4 \mathrm{e}$, respectively). Analogously, the distances for the reduced species were $3.06 \AA$ for $[\mathrm{Cu} \text { (pyalen) }]^{+}$and $3.14 \AA$ for $[\mathrm{Cu}(\text { apzpn })]^{+}$(considering Figures $4 \mathrm{~d}$ and $4 \mathrm{f}$ respectively). Anyway, the differences among the oxidized and reduced species are not very significant.

In order to check the copper complexes arrangement in relation to the clay layers, a LPN sample saturated with $[\mathrm{Cu} \text { (pyalen) }]^{2+}$ complex was prepared (i.e., $100 \%$ of the clay's CTC was neutralized by the cationic complex). The XRD pattern of the saturated solid sample (data not shown) shows a diffraction peak related to a basal spacing $\left(\mathrm{d}_{001}\right)$ equal to $12.8 \AA$ A. Considering the inorganic layer thickness $(9.6$ $\AA$ ), the metal complex ion is confined in a space of approximately 3.2 $\AA$. According to the computational simulation data of $[\mathrm{Cu}(\text { pyalen })]^{\mathrm{n}+}$ ( $n=1$ or 2 ) dimensions, above described, the cation should assume a parallel orientation between the layers, corroborating the EPR data (Figure 3); a higher basal spacing is expected if the $\mathrm{N}_{4}$ plane of the organic ligand is perpendicularly oriented.

EPR spectroscopy is a valuable technique for copper(II) species characterization, but not adequate to study copper(I) compounds. On the other hand, $\mathrm{x}$-ray absorption near edge spectroscopy (XANES) is mostly used to characterize copper(I) compounds such as metal enzymes, once it is sensitive to the oxidation state, and the geometry around the absorbing metal. ${ }^{34,35}$ Figure 5 and Figure 1S (Supplementary Material) show the XANES spectra recorded for the free copper complexes and the corresponding immobilized derivatives. XANES allows the simultaneous detection of both copper oxidation states. a)

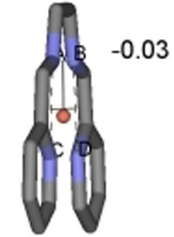

c)

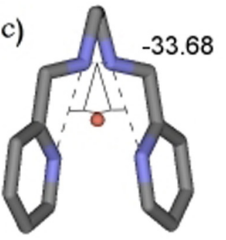

e)

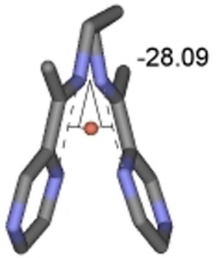

b)
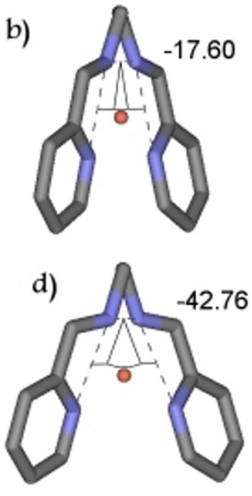

f)

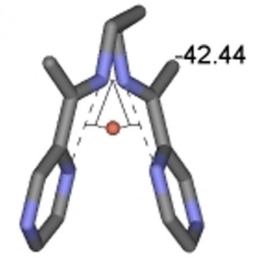

Figure 4. Theoretical structures for $[\mathrm{Cu}(\text { pyalen })]^{2+}(\mathrm{a}$ and $b),\left[\mathrm{Cu}(\text { pyalen }]^{+}\right.$ $(c$ and $d) ;[\mathrm{Cu}(\text { apzpn })]^{2+}(e) ;[\mathrm{Cu}(\text { apzpn })]^{+}(f)$. Torsion angles between $\mathrm{N}_{4}$ atoms are shown in degrees, and $H$ atoms are hidden for better visualization

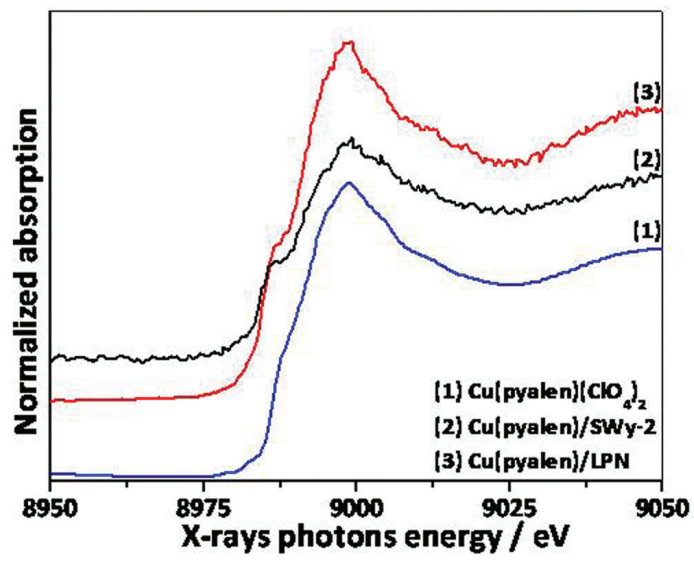

Figure 5. Cu K edge XANES spectra of the Cu(II) Schiff-base complex, free and immobilized in the clays. (1) [Cu(pyalen)](ClO$)_{2}$, (2) [Cu(pyalen)]/ SWy-2 and (3) [Cu(pyalen)]/LPN

XANES spectra point out only the presence of copper(II) for the free complexes, as it is expected. However, the spectra of the immobilized complexes in LPN and SWy-2 clays show signals from both copper(I) and copper(II): the shoulder at $c a$. $8985 \mathrm{eV}$ is characteristic of copper(I) while the copper(II) edge can be seen at $c a .8990 \mathrm{eV} .^{34}$ The main difference between the XANES spectra of an oxidized and a reduced copper ion is a shoulder in energy below that of metal edge, around $8983 \mathrm{eV}$, observed for the reduced copper(I) but not for the oxidized metal. ${ }^{36}$ This pre-edge absorption is attributed to a $1 \mathrm{~s} \rightarrow 4 \mathrm{~s}$ electronic transition. XANES spectrum of copper(II) ion shows the first intense transition at $8986 \mathrm{eV}$, assigned to a $1 \mathrm{~s}$ to $4 \mathrm{~s}$ transition or $1 \mathrm{~s}$ to $4 \mathrm{p}$ transition. ${ }^{36}$ Although it is possible to determine the presence of both copper(I) and copper(II) complexes in the immobilized $\left[\mathrm{Cu}(\text { pyalen) }]^{2+}\right.$ (Figure 5), a predominance of the copper(I) complex can be observed. While the [Cu(apzpn)]/ LPN sample resembles that of the free complex (Figure 1S), with more contribution of the copper(II) to the spectrum (pre-edge at $8983 \mathrm{eV})$, the $[\mathrm{Cu}($ apzpn) $] / \mathrm{SWy}-2$ shows a pronounced band at $8985 \mathrm{eV}$ attributed to the copper(I) complex. The pre-edge at 8985 
$\mathrm{eV}$ has low intensity, indicating that the copper(II) complex is predominating in interaction with the clay. The relative amount of copper(I) differ for each complex/clay system, and it is higher for the $[\mathrm{Cu}($ pyalen $)] /$ clay samples.

Taking into account the presence of copper(I) sites in the clay samples, a water solution of $[\mathrm{Cu} \text { (pyalen) }]^{2+}$ ion was reduced in a cuvette containing a bead of amalgamated zinc, in order to record the spectrum of the reduced complex. Spectral modifications (Figure 2S) revealed the development of new bands in the UV/Vis regions: a shoulder at $370 \mathrm{~nm}$, and an intense band at $480 \mathrm{~nm}$, comparable to those observed in Figure 2. The same results were obtained under inert atmosphere. After approximately two hours, the copper complex solution was separated from the zinc bead and the two phases were observed. The red-brown solution become blue again while the zinc bead was covered by a red material, latter characterized as copper metal. Similar spectra were also obtained when the $[\mathrm{Cu}(\text { pyalen })]^{2+}$ complex reacts with the albumin protein or glutathione in solution. ${ }^{37}$

The spectral properties of reduced Schiff base-copper(II) complexes were also explored through computational simulation. The DFT ab-initio CP-PAW methodology used here can only reliably reproduces ground state properties and, therefore, it is not able to describe the optical excitations observed in an UV/VIS spectrum. The "Zerner's Intermediate Neglect of Differential Overlap" (ZINDO) $)^{38}$ method was used, as embodied in the Cerius 2 computational packa$\mathrm{ge}^{39}$ parameterized for spectroscopy (INDO/S) at the configuration interaction (CI) level, to obtain the UV/VIS spectra. The three different geometries for the $[\mathrm{Cu}(\text { pyalen })]^{\mathrm{n}+}$ complex, indicated at Figures 4b-d, were considered to simulate some possible constrained molecule configurations observed for the metal complex in the clay, but only the spectra for the $1+$ charge state were calculated. These calculations were performed including simple excitations in the spectra with 30 occupied and 30 unoccupied orbitals. In Figure 3S, supplementary material, the $[\mathrm{Cu} \text { (pyalen) }]^{+}$spectra obtained with the 100 highest oscilator strength are shown.

First, it was noticed that for the two more distorted (Figures $4 \mathrm{c}$ and $4 \mathrm{~d}$ ) geometries, there is an absorption in the visible region which is not present in the less distorted (Figures $4 \mathrm{a}$ and $4 \mathrm{~b}$ ) cases. The transitions in the UV region are almost not modified. In Figure 6 it is shown the molecular orbitals related with the most relevant optical transitions obtained in the $42.76^{\circ}$ torsion angle geometry. The transition seen at $536.08 \mathrm{~nm}$ (in the visible region) is from the highest occupied molecular orbital (HOMO) to the lowest unoccupied molecular orbital (LUMO). The HOMO orbital presents a mixed $d$ and $\pi$ character, whereas the LUMO presents mostly $\pi$ character with a metal to ligand charge transfer (MLCT) excitation band. The second transition (from the orbital 50 to the 53 , at $325.41 \mathrm{~nm}$ ) has similar character while the fourth (from the orbital 48 to the 51, at 297.28 $\mathrm{nm}$ ) and fifth (from 49 to 52 orbital at $290.63 \mathrm{~nm}$ ) are $\pi-\pi^{*}$ bands. The same qualitative result was obtained for the $[\mathrm{Cu}(\text { apzpn })]^{+}$complex (not shown) where the HOMO-LUMO transition is at $557.40 \mathrm{~nm}$ and the largest oscillator strength is seen at the $\pi-\pi^{*}$ band at $304.03 \mathrm{~nm}$.

These spectra indicate that the visible transition around 500-550 $\mathrm{nm}$ is allowed only for more distorted geometries, and that the others transitions (in the UV range) do not change significantly. Differences observed in the wavelengths calculated regarding the experimental values, can be assigned to the presence of solvent molecules around the complexes, not considered in the theoretical calculations. It is also important to remember that the organic ligand is probably oxidized in the copper(I) formation reaction but this fact was not considered in the calculations.

All the data reported up to now permit to conclude that the spectral modifications observed when the Schiff base-copper(II) complexes are intercalated into LPN or SWy-2 clays are due to the

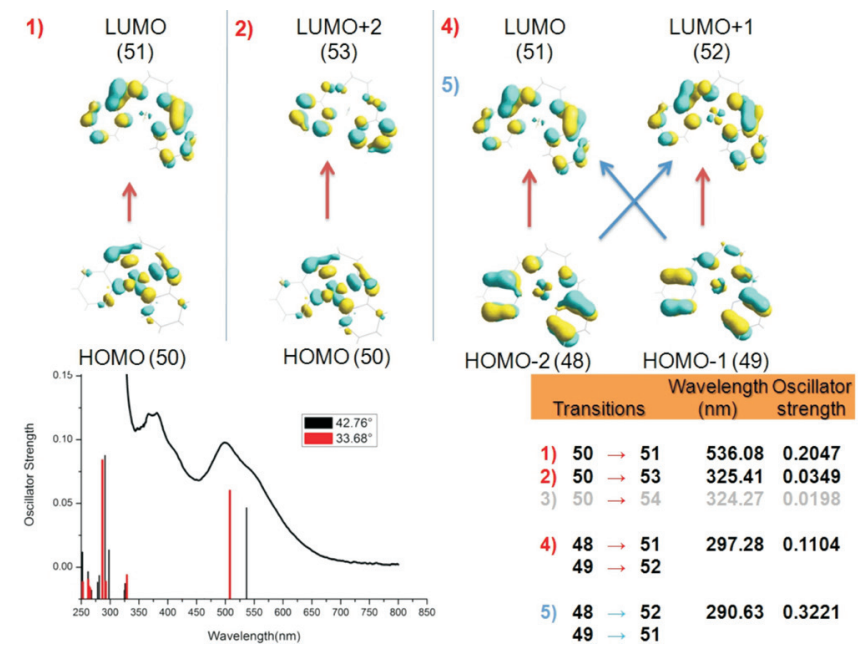

Figure 6. Lower left panel, theoretical optical transitions (thin lines) for $[\mathrm{Cu}(\text { pyalen })]^{+}$obtained using the $33.68^{\circ}$ and $42.76^{\circ}$ torsion angle structures superposed to the experimental absorption spectra. Lower right panel, the most relevant transitions in the spectra (orbitals denoted by 48 to 54) and in the upper panel, the corresponding molecular orbitals. Results shown in the upper panel and in the lower right panel were obtained using the $42.76^{\circ}$ structure

formation of copper(I) species. Next point to be discussed in this study regards about the nature of the reducing agent. Working with a natural clay such as SWy-2, a montmorillonite with sodium cation in the interlayer region and some metal transition cations (like iron ion) in the intralayer structure or as impurities, it would be possible to presume a redox reaction between the copper(II) complex and the inorganic matrix. However, changes also occur using the synthetic Laponite clay, whose nanosized particles contain no impurity and the chemical elements in inter- or intralayer sites are no oxidable. ${ }^{21}$ It was worthless to deintercalate the copper species from the smectite clays via ion exchange reaction with a concentrated $\mathrm{NaCl}$ solution. No colored species were observed during the reaction time, suggesting a strong interaction between the metal complexes and the inorganic structures. Hence, it was not possible to extract the copper species to perform an ex-situ characterization study. Modifications in the organic di-imine ligand could be verified by vibrational spectroscopy. FTIR spectra of the Schiff base-copper(II) complexes intercalated into LPN or SWy-2 are dominated by the absorption of the inorganic layered silicate (data not shown). Bearing in mind that the Raman scattering of clay is low, the Raman spectra of the immobilized complexes were also recorded. Unfortunately, the samples showed fluorescence emission and no relevant bands were observed. However, the presence of copper(I) complex in the clays is once again confirmed, since copper(I) compounds emit light when a MLCT (metal to ligand) band is excited.

Therefore, the photoluminescence behavior of the Schiff-base copper complexes immobilized in clays was studied in solid state at room temperature. The spectral patterns are depicted in Figure 7. In a general way, blue structured emissions near $440 \mathrm{~nm}$ were observed $\left(\lambda_{\text {excitation }}\right.$ at $\left.374 \mathrm{~nm}\right)$ and assigned to metal to ligand charge transfer (MLCT) transitions, typical of $d^{10} \operatorname{copper}(\mathrm{I})$ systems. ${ }^{40}$

However, the photoluminescence spectra obtained for the $[\mathrm{Cu}(\mathrm{apzpn})] / \mathrm{LPN}$ sample revealed a different pattern. As shown in Figure 4S, this sample exhibited a broad emission band centered at $580 \mathrm{~nm}$, and excitation bands at 278, 325sh, 375, 420sh and 490 $\mathrm{nm}$. Considering that the free complex $[\mathrm{Cu}(\text { apzpn })]^{2+}$ also exhibited a very weak emission in the same spectral range $(525-600 \mathrm{~nm})$, it is suggested that the large red-shift observed to emission band in the $[\mathrm{Cu}(\mathrm{apzpn})] / \mathrm{LPN}$ sample may be attributed to the presence of 


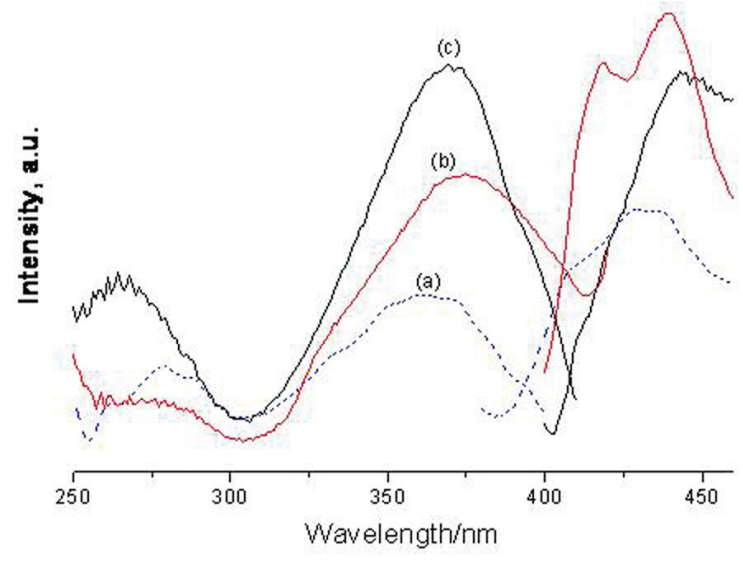

Figure 7. Excitation and emission spectra of [Cu(pyalen)]/LPN (a), $[\mathrm{Cu}($ pyalen)]/SWy2 (b) and [Cu(apzpn)]/SWy2 (c), solid state at $298 \mathrm{~K}$

copper(II) species. Indeed, in the literature it was already reported luminescent properties of copper(II) complexes containing Schiff bases. ${ }^{41}$

It is worth mentioning that these results are in accordance with XANES data that revealed a predominance of the copper(I) complex in immobilized $[\mathrm{Cu}(\text { pyalen })]^{2+}$ systems. Besides, when in this work the $[\mathrm{Cu} \text { (pyalen) }]^{2+}$ ion was immobilized in Laponite, a red color characteristic of copper(I) systems was detected. Morshedi et al..$^{42}$ have recently reported that the copper(I) complex containing Schiff base $[\mathrm{Cu}$ (ca2dapte) $] \mathrm{ClO}_{4}$, (ca2dapte $=\mathrm{N}, \mathrm{N}^{\prime}$-bis(trans-cinnamaldehyde)1,2-di(o-iminophenylthio)ethane) is also dark red. Since no $d-d$ transitions are expected for $\mathrm{d}^{10}$ complexes, the absorption band observed at $497 \mathrm{~nm}$ in UV/Vis spectrum of [Cu(pyalen)]/LPN sample, responsible for the red color, can be assigned to MLCT transition. ${ }^{43}$

Although it was not possible to identify the chemical modification in the ligand promoted by the intercalation process, the subject deserves some considerations. An analogous copper complex synthesized by reacting 1,3-diaminepropane and 2-acetylpyridine in the presence of copper(II) (abbreviated $\left[\mathrm{Cu}(\text { apyen) }]^{2+}\right.$ ) was also intercalated in Laponite. ${ }^{44}$ The unique difference between $[\mathrm{Cu}(\text { pyalen })]^{2+}$ and $[\mathrm{Cu} \text { (apyen) }]^{2+}$ is the presence of methyl groups $\left(-\mathrm{CH}_{3}\right)$ instead of hydrogen atoms bounded to the carbon atoms of imine groups $\mathrm{C}=\mathrm{N}$ (Figure 1B). While the band at $350-400 \mathrm{~nm}$ in the spectrum of $[\mathrm{Cu}(\text { pyalen })]^{2+}$ in Laponite suspension is very defined after about 90 min of reaction (Figure 2), similar modification (bands at about 360-380 nm) was observed only after five days working with $[\mathrm{Cu} \text { (apyen) }]^{2+}$. This experimental information suggests that the imine group of the Schiff base molecule can be related to the intramolecular redox reaction between the copper center and the ligand. Indeed, the oxidation of amine molecule to nitrile was observed in zeolites containing copper(II), ${ }^{45}$ indicating that the Schiff base oxidation is a reasonable proposition.

\section{CONCLUSIONS}

XANES spectroscopy allowed the observation of both copper(I) and copper(II) complexes immobilized in inorganic host structures, complemented and corroborated by EPR and electronic spectroscopy results. These experimental data evidenced that clay environment can promote the partial metal reduction and simultaneous Schiff base ligand oxidation, and additionally provide the stabilization of resulting copper(I) species. Those observations can be relevant for the preparation of catalysts, useful in the oxidation of selected substrates for industrial or environmental purposes.

\section{SUPPLEMENTARY MATERIAL}

Available at http://quimicanova.sbq.org.br, in PDF format, with free access.

\section{ACKNOWLEDGEMENTS}

The authors are grateful to Fundação de Amparo à Pesquisa do Estado de São Paulo (FAPESP, Grant 05/60596-8), Coordenação de Aperfeiçoamento de Pessoal de Nível Superior (CAPES), and Conselho Nacional de Desenvolvimento Científico e Tecnológico (CNPq) for financial support, and fellowships to this work. Also, they would like to thank the Brazilian Synchrotron Light Laboratory (LNLS, project XAS 1186/02) for the XAS beam line time. A. M. D. C. Ferreira was also supported by the Programa Institutos Nacionais de Ciência e Tecnologia - CNPq/ FAPESP/MCT (INCT Processos Redox em Biomedicina - Redoxoma).

\section{LIST OF ABBREVIATIONS}

DFT - Density Functional Theory

DMPO - 5,5'-dimethyl-1-pyrroline-N-oxide

DPPH - $\alpha, \alpha^{\prime}-$ diphenyl- $\beta$-picrylhydrazyl

EPR - electron paramagnetic resonance

SOD1 - Cu,Zn- superoxide dismutase

$\mathrm{UV} / \mathrm{Vis}$ - electronic spectroscopy in the ultraviolet and visible range

XANES - X-ray absorption near edge structure

\section{REFERENCES}

1. Bergaya, F.; Theng, B. K. G.; Lagaly, G., eds.; Handbook of Clay Science, Elsevier: Amsterdan, 2006, vol. 1.

2. Fraile, J. M.; García, J. I.; Herrerías, C. I.; Mayoral, J. A.; Pires, E.; Chem. Soc. Rev. 2009, 38, 695.

3. Say, R.; Birlik, E.; Denizli, A.; Ersöz, A.; Appl. Clay Sci. 2006, 31, 298.

4. Erdem, M.; Say, R.; Ersöz, A.; Denizli, A.; Türk, H.; Appl. Clay Sci. 2010, 47, 223.

5. Iwasa, N.; Yamane, T.; Takei, M.; Ozaki, J.; Arai, M.; Int. J. Hydrogen Energy 2010, 35, 110.

6. Iwasa, N.; Takizawa, M.; Arai, M.; Appl. Catal., A 2006, 314, 32.

7. Iwasa, N.; Kubota, T.; Bando, K.K.; Shirai, M.; J. Phys. Chem. Solids 2004, 65, 503

8. Crestini,C.; Pastorini, A.; Tagliatesta, P.; Eur. J. Inorg. Chem. 2004, 22 , 4477.

9. Fraile, J. M.; García, J. I.; Harmer, M. A.; Herrerías, C. I.; Mayoral, J. A.; Reiser, O.; Werner, H.; J. Mater. Chem. 2002, 12, 3290.

10. Maiti, D.; Woertink, J. S.; Sarjeant, A. A. N.; Solomon, E. I.; Karlin, K. D.; Inorg. Chem. 2008, 47, 3787.

11. Massa, W.; Dehghanpour, S.; Jahani, K.; Inorg. Chim. Acta 2009, 362, 2872.

12. Che, C. M.; Mao, Z.; Miskowski, V. M.; Tse, M. C.; Chan, C. K.; Cheung, K. K.; Phillips, D. L.; Leung, K. H.; Angew. Chem., Int. Ed. 2000, 39, 4084.

13. Ford, P. C.; Vogler, A.; Acc. Chem. Res. 1993, 23, 220.

14. Guerriero, P.; Tamburini, S.; Vigato, P. A.; Coord. Chem. Rev. 2004, 248 , 1717.

15. Gupta, K. C.; Sutar, A. K.; Coord. Chem. Rev. 2008, 252, 1420.

16. Santos, M. L. P.; Faljoni-Alário, A.; Mangrich, A. S.; Ferreira, A. M. D. C.; J. Inorg. Biochem. 1998, 71, 71.

17. Santos, M. L. P.; Bagatin, I. A.; Pereira, E. M.; Ferreira, A. M. D. C.; J. Chem. Soc., Dalton Trans. 2001, 838.

18. Azzellini, M. A. A.; Bagatin, I. A.; Ferreira, A. M. D. C.; Redox Report 2006, 11, 25. 
19. Bizeto, M. A.; Alves, W. A.; Barbosa, C. A. S.; Ferreira, A. M. D. C.; Constantino, V. R. L.; Inorg. Chem. 2006, 45, 6214.

20. Brindley, G. W.; Brown, G., eds.; Crystal Structures of Clay Minerals and their X-Ray Identification, Mineralogical Society: London, 1984, Monograph no. 5.

21. Dias, P. M.; Faria, D. L. A.; Constantino, V. R. L.; Clays Clay Miner. 2005, 53, 362.

22. Blöchl, P. E.; Phys. Rev. B 1994, 50, 17953.

23. Kohn, W.; Sham, L. J.; Phys. Rev. 1965, 140, 1133.

24. Perdew, J. P.; Burke, K.; Ernzerhof, M.; Phys. Rev. Lett. 1996, 77, 3865.

25. da Silveira, V. C.; Caramori, G. F.; Abbott, M. P.; Gonçalves, M. B.; Petrilli, H. M.; Ferreira, A. M. D. C.; J. Inorg. Biochem. 2009, 103, 1331.

26. Schimpl, J.; Petrilli, H. M.; Blöchl, P. E.; J. Am. Chem. Soc. 2003, 125, 15772.

27. Lange, J.; Elias, H.; Paulus, H.; Muller, J.; Weser, U.; Inorg. Chem. 2000, 39, 3342.

28. Ferreira, A. M. D. C.; Krumholz, P.; Riveros, J. M.; J. Chem. Soc., Dalton Trans. 1977, 896.

29. Rupert, R. P.; J. Phys. Chem. 1973, 77, 784.

30. Johnston, C. T.; Tipton, T.; Stone, D. A.; Erickson, C.; Trabuet, S. L.; Langmuir 1991, 7, 289.

31. Muller, J.; Felix, K.; Maichle, C.; Lengfelder, E.; Strähle, J.; Weser, U.; Inorg. Chim. Acta 1995, 233, 11.

32. Giannels, E. In Materials Chemistry, an Emerging Discipline; Interrante, L. V.; Casper, L. A.; Ellis, A. B., eds.; American Chemical Society: Washington DC, 1995, chap. 10.
33. Schoonheydt, R. A.; Pelgrims, J.; J. Chem. Soc., Faraday Trans. 1983 , $79,1169$.

34. Kau, L-S.; Spira-Solomon, D. J.; Penner-Hahn, J. E.; Hodgson, K. O.; Solomon, E. I.; J. Am. Chem. Soc. 1987, 109, 6433.

35. Cezar, J. C.; Vicentin, F. C.; Tolentino, H. C. N.; Rev. Bras. Ens. Fís. 2000, 22, 363.

36. Ascone, I.; Castaner, R.; Tarricone, C.; Bolognesi, M.; Stroppolo, M. H.; Desideri, A.; Biochem. Biophys. Res. Commun. 1997, 241, 119.

37. Azzellini, M. A. A.; Abbott, M. P.; Machado, A.; de Miranda, M. T. M; Garcia, L. C.; Caramori, G. F.; Gonçalves, M. B.; Petrilli,H. M.; Ferreira, A. M. D. C.; J. Braz. Chem. Soc. 2010, 21, 1303.

38. Anderson, W. P.; Edwards, W. D.; Zerner, M. C.; Inorg. Chem. 1986, 25, 2728.

39. ZINDO module from CERIUS2 package; http://www.accelrys.com, acessada em Julho e Outubro 2010.

40. Habib, H. A.; Hoffmann, A.; Hoppe, H. A.; Steinfeld, G.; Janiak, C.; Inorg. Chem. 2009, 48, 2166.

41. Rahaman, S. H.; Fun, H.-K.; Ghosh, B. K.; Polyhedron 2005, 24, 3091.

42. Morshedi, M.; Amirnasr, M.; Slawin, A. M. Z.; Woollins, J. D.; Khalaji, A. D.; Polyhedron 2009, 28, 167.

43. Del Paggio, A. A.; McMillin, D. R.; Inorg. Chem. 1983, 22, 691.

44. Note: Complex $[\mathrm{Cu}(\text { apyen })]^{2+}$ was prepared by the same method described for the other complexes, with $54 \%$ yield; Elemental analysis: C, 35.17\%; H, 3.80\%; N, 10.24\%; Calc. for $\left[\mathrm{Cu}\left(\mathrm{C}_{16} \mathrm{H}_{18} \mathrm{~N}_{4}\right)\right]\left(\mathrm{ClO}_{4}\right)_{2} \cdot \mathrm{H}_{2} \mathrm{O}$; FW, 528.79; C, 35.14\%; H, 3.68\%; N, 10.24\%.

45. Kanazirev, V. I.; Price, G. L.; Dooley, K. M.; J. Catal. 1994, 148, 164 